\title{
Connecting Idaho With the Sea
}

\author{
Completion of the Celilo Canal Along the Columbia River
}

By Fred W. Vincent

T HE largest lock canal in the West has just been Tompleted by the side of the Columbia River just above the Dalles, Oregon. This waterway makes the Columbia River navigable continuously for 500 miles from the sea. It is eight and one half miles in length, and was constructed at a total cost of approximately $\$ 5,000,000$. The construction period ranged over almost a decede, and the opertions have progred with practically no interruption since The canal was formally opened to traffic on May 5th, with elaborate ceremonies in which all parts of the 300,000 square miles of territory comprising the Columbia basin were represented by prominent citizens.

Through the operation of the canal the inland state of Idaho enters the caterory of commonwealths that boast a seaport, as vessels of the river stern theel pal upper tributary of the Columbia, a distance of 480 miles.

The construction of this canal was by no means a simple task, and its successful completion reflects great credit upon our army engineers. For a length of about fome cases it was hecessary to make cuts seventy feet deep.

The Columbia, which is the third largest river in the country, has a drop of ninety feet in eight miles,

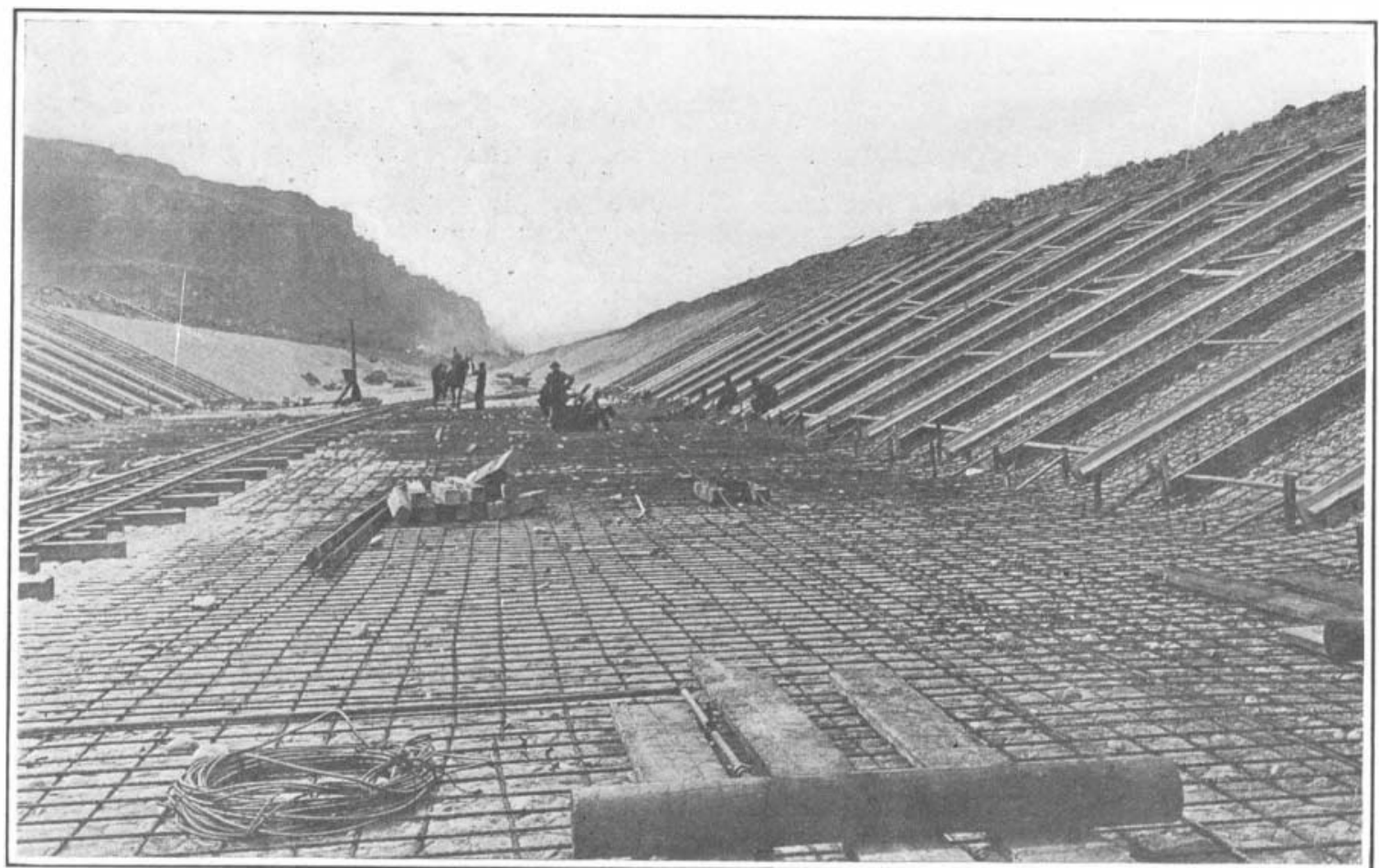

Reinforced concrete paving through the sand belt.

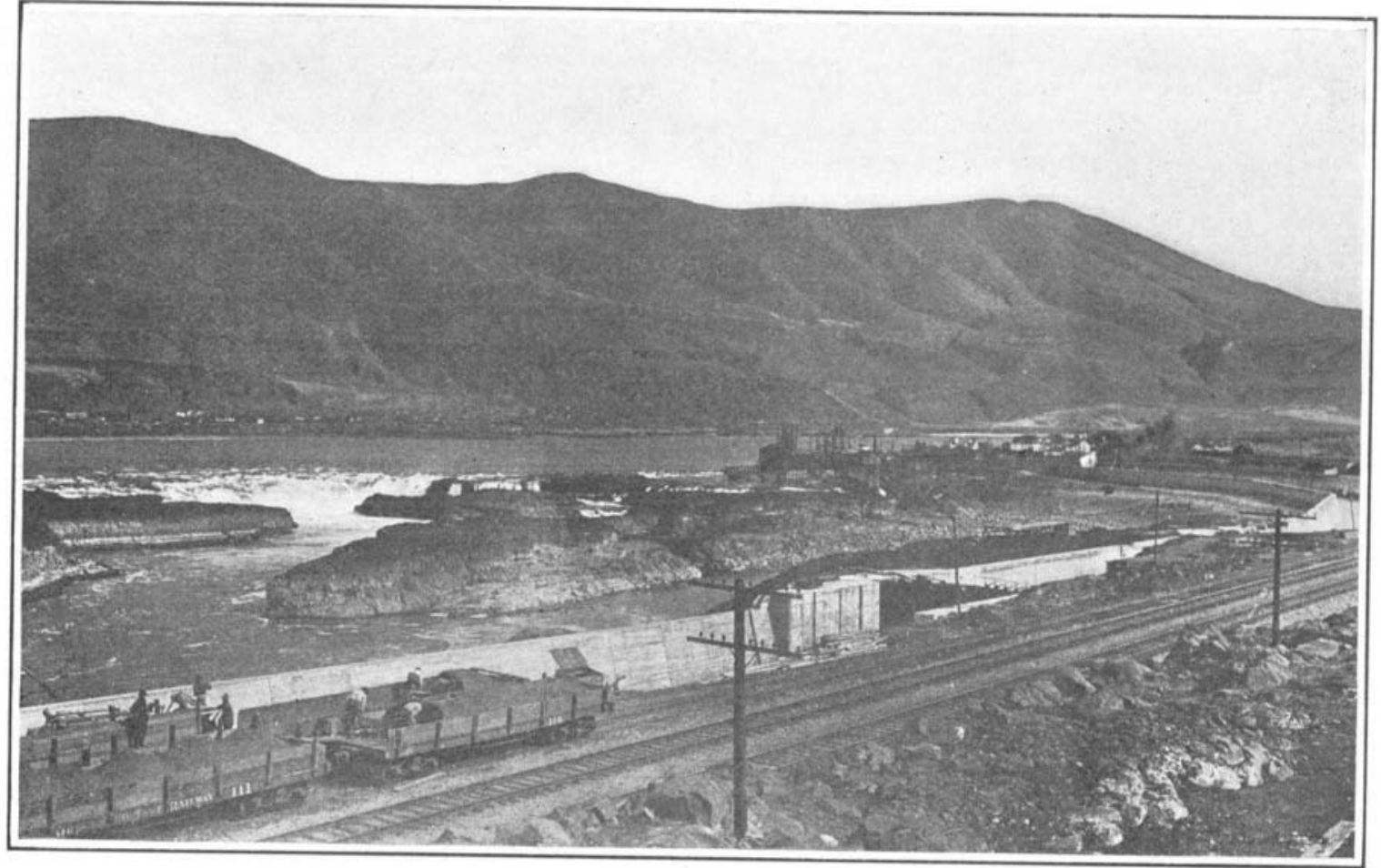

Upper portion of the canal, showing the Celilo Falls.
Rapids, Washington and Kettle Falls. This done the Columbia will come to be numbered as the longest navigable river in the United States, except the Mississippi, and the great inland empire of the Northwest will enjoy the advantages of a waterway to carry its fruits, timber, wheat, wool, and livestock to the seaboard.

\section{The Miracle of Bird Migration}

، 7 TE mystery of bird migration has proved a fas1 cinating subject for speculation and study from the earliest times," writes Mr. Wells W. Cooke in a very comprehensive and instructive publication just issued by the Department of Agriculture (Bulletin No. 185, "Bird Migration"), "but fuller knowledge has served to increase rather than to lessen interest in the subject. More persons to-day are watching birds and noting their times of arrival and departure than ever nefore before. Indeed, the Bus received migration notes from more than 2,000 different observers. The Survey has been collecting data on bird migration for more than twenty-five years. Investigations by its field naturalists extending over the North American continent from Panama to the Arctic Circle have resulted in voluminous notes, and in addition the assistance of ornithologists throughout the country has been enlisted."

Thus, a great body of information is now available, concerning not only the migratory habits of birds in where it passes through the Cascade Range. After a series of falls and rapids it is compelled to traverse channel only 165 feet wide for three miles, while its normal width is almost a mile. Through this narrow are made up of lava, a solidified stream that in centuries past flowed across the wide valley and dammed the mighty river. When the engineers surveyed the site they found what was not rock was shifting sand The rock question was merely a matter of dynamite and the sand and gravel question was settled by lining the canal with concrete reinforced by heavy steel.

This work called for the excavation of practically $1,000,000$ cubic yards of solid lava rock, 504,000 cubic yards of common dry excavating, and 536,000 cubic yards of sand. As many as 1,500 men were at work at one time, and eight steam shovels, 22 locomotives and 200 cars were used. There are 5 locks, with eight passing basins. The minimum depth of water is 8 feet and the ordinary width of the canal is 45 feet. Each lock is 300 feet in length. The principal locks end of tandem locks, or two locks, that give a lift of 70 feet out of the total 90 -foot fall that the canal overcomes.

Now that the Celilo bar to navigation is overcome, the next step in freeing the Columbia as far as Revelstoke, British Columbia-1,000 miles from the oceanwill be the removal of the obstructions at Priest River

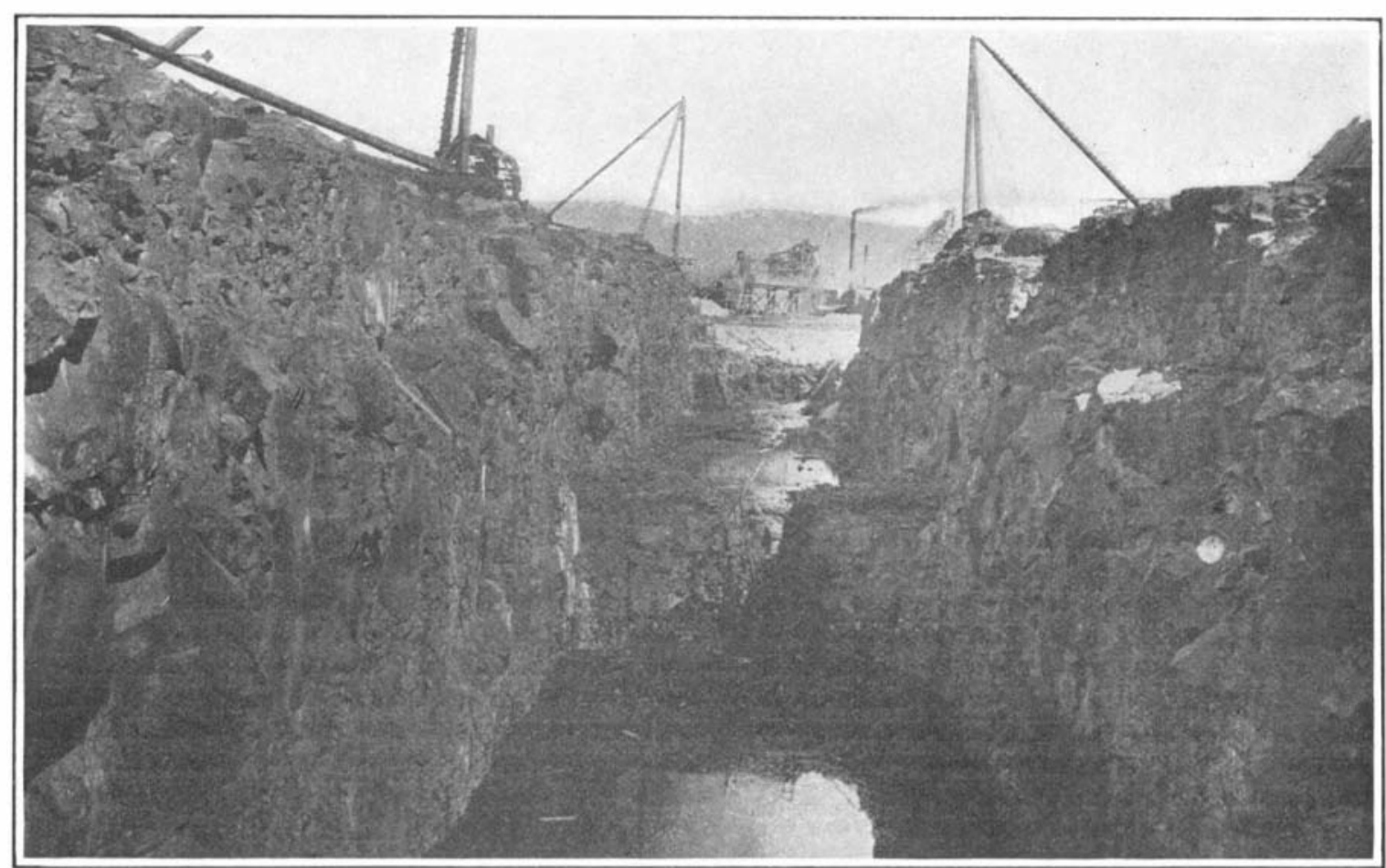

Looking west through Five Mile locks. 
general, but of each species separately, viz., the locations of breeding grounds and winter homes, dates and speeds of migration (the latter in many cases varying greatly for different parts of the flight), the principal routes, and the relations of all these things to meteorological and geographical conditions, the distribution of food, and other circumstances. The text and numerous charts of Mr. Cooke's memoir present this information in much detail.

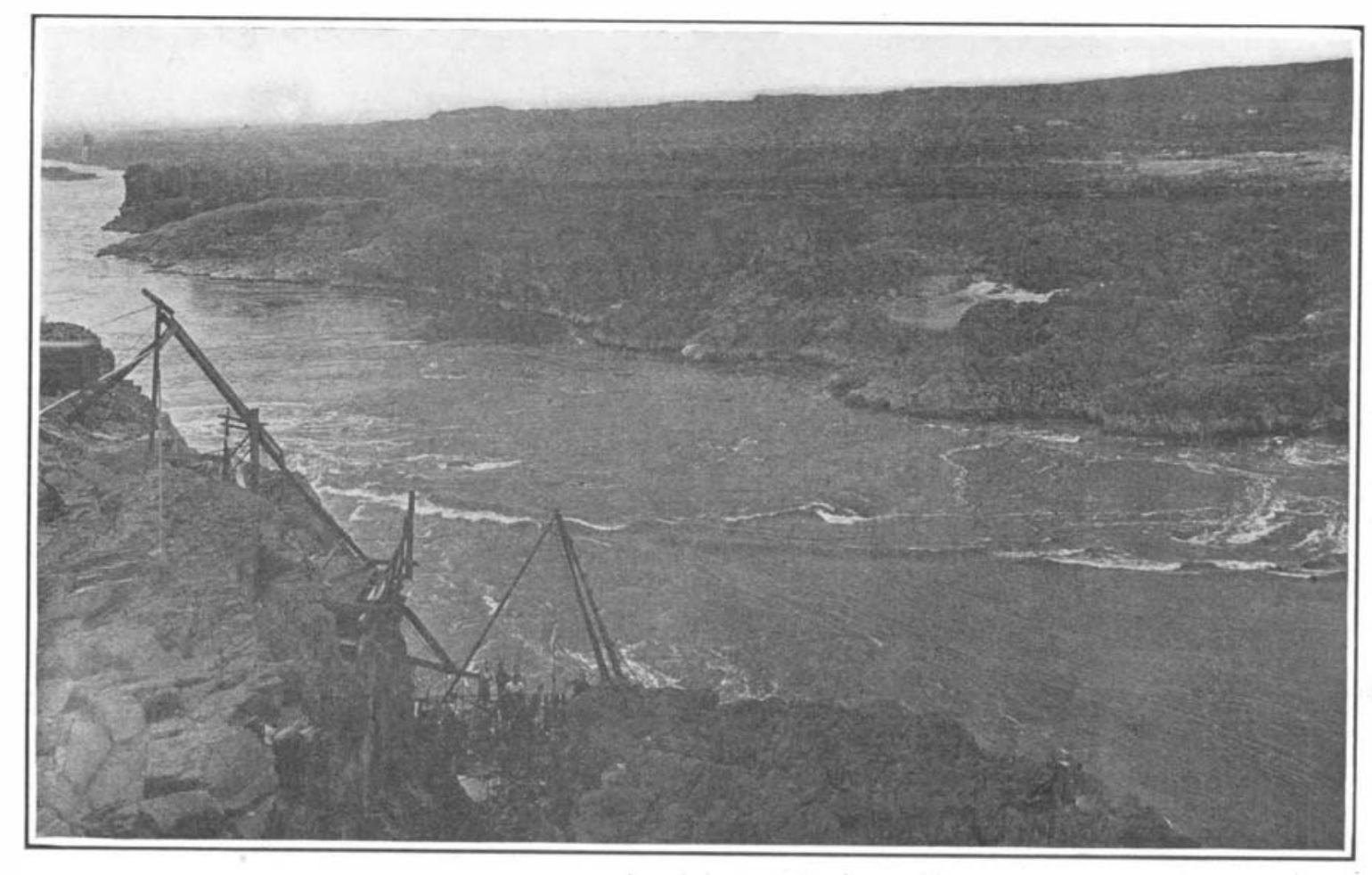

Five Mile Rapids, where the Columbia is 165 feet wide and 200 feet deep.
The favorite highway extends straight across the Gulf of. Mexico, and recent evidence disproves the old belief that after traversing this and similar stretches of water most birds are exhausted and promptly seek the ground. In fact, with increasing knowledge of birl migration, we are more and more impressed with the wonderful efticiency of the bird as a flying-machine. Of the golden plover, which in favorable weather flies 2,400 miles over the ocean from Nova Scotia to South America without

The differences between the habits of various species are striking. As to the distances covered in migration, we have at one extreme a few non-migratory species, such as the grouse, bobwhite, cardinal, and Carolina wren, and at the other that marvelous traveler, the Arctic tern, which nests within a few degrees of the north pole, and migrates thence to the borders of the Antarctic continent. The Aretic tern makes its annual fight; hence, even if it flew in a straight line, it would need to cover more than 150 miles a day. Actually this distance is doubtless multiplied several times by zigzag twistings and turnings in pursuit of food. A noteworthy fact in connection with this bird is that it enjoys more hours of daylight and sunlight every year than any other animal on the globe. During at least eight months it lives where there is no night, and during the other it lives wher the four months where daylight is much longer than
darliness.

The dates of migratory movements are determined by average weather rather than by that which happens to prevail during the season of migration in any particular year. Thus, migration may be said to be a question of climate and not weather. However, after a bird's travel begins the weather encounterel en routo influences the process in a subordinate way, retarding or accelerating advance by not more than a few days in the aggregate. The winds seem to have little to do with the process.

Different species affect different routes of migration.

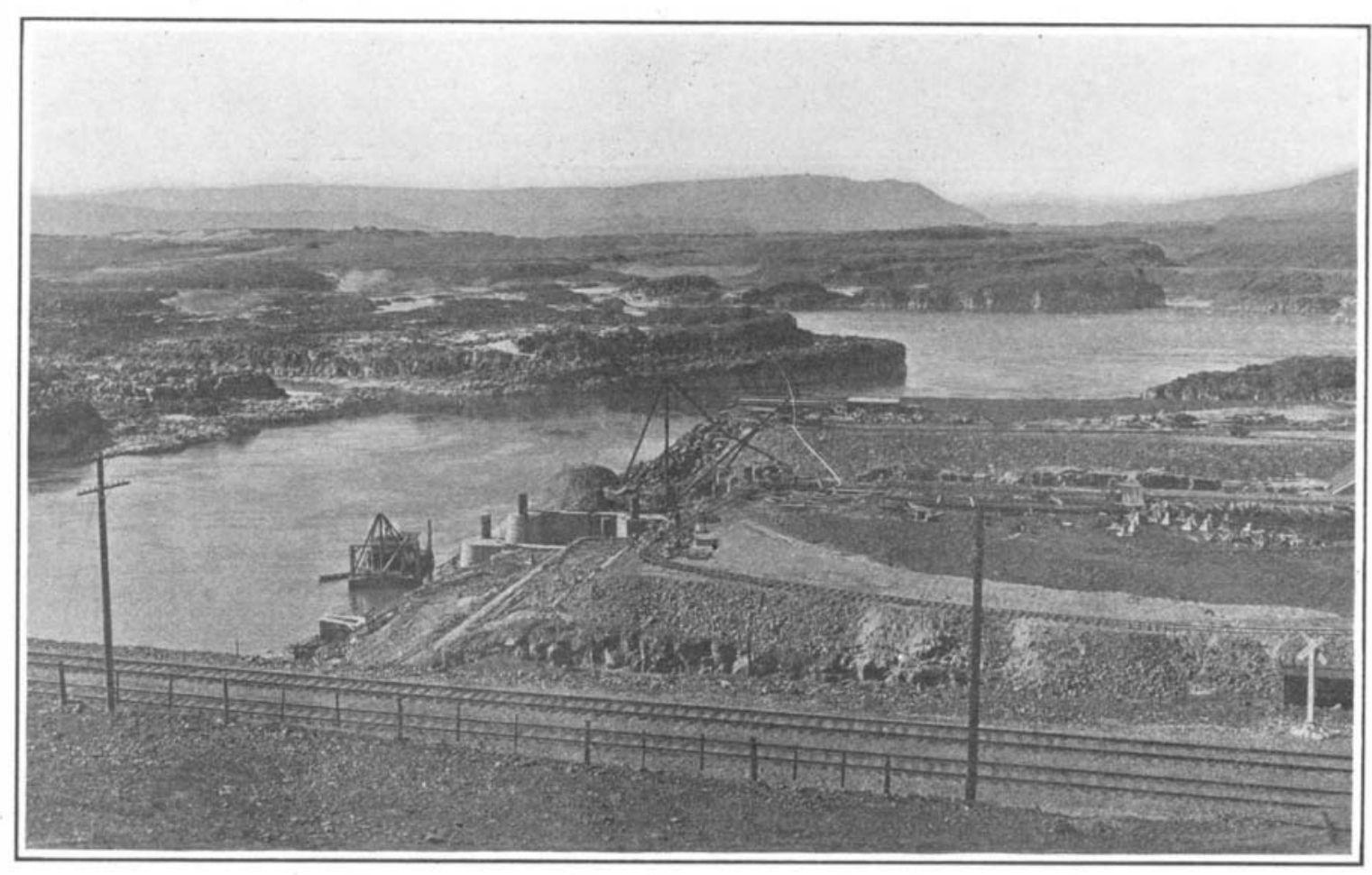

Lower end of the Celilo canal, showing work on the locks.

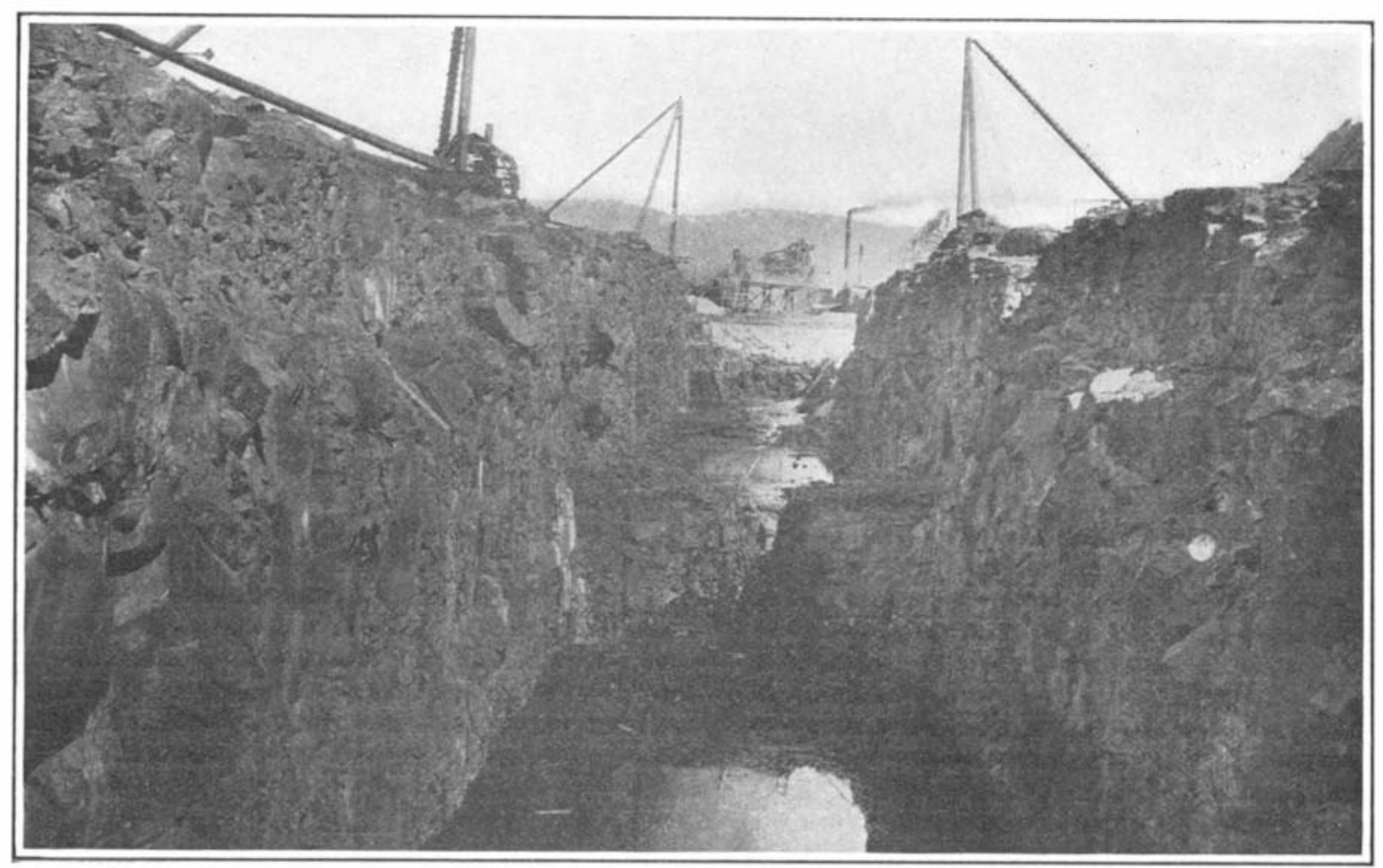

A 70-foot cut through solid lava at the western end of the canal. a stop, probably spending some forty-eight hours on the wing, Mr. Cooke says:

"Here is an aerial machine that is far more economical of fuel, i. e., of energy, than the best aeroplane yet invented. The to-and-fro motion of the bird's wing appears to be an uneconomical way of applying power. since all the force required to bring the wing forward for the beginning of the stroke is not only wasted, but more than wasted, as it largely increases the air friction and retards speed. On the other hand, the screw propeller of the aeroplane has no lost motion. Yet less than two ounces of fuel in the shape of body fat suffice to force the bird at a high rate of speed over that 2,400-mile course. A thousand-pound aeroplane, if as economical of fuel, would consume in a 20 -mile flight not the gallon of gasoline required by the best machines, but only a single pint."

How do migrating birds find their way? This is the greatest mystery of all. The familiar inhabitants of our dooryard martin boxes will return next year to these same boxes, though in the meantime they have visited Brazil, flying by night and crossing a great body of water where there are no marks to guide them. So many hypotheses have been advanced on this strange subject (one of the latest of which regards birds as natural compasses having a subtle response to the earth's magnetic lines of force), that we turn with interest to the latest authoritative opinion, as given by Mr. Cooke. Sight, he says, undoubtedly plays a part in the process, by night as well as by day. "Nevertheless something besides sight guides these travelers of the upper air." They possess a power, whatever its nature, which may be called a sense of direction. "We recognize in ourselves the possession of "some such sense, though imperfect and frequently at fault."

\section{Russia and Alcohol Utilization} ONSUl-GENERAL JOHN H. SNODGRASS of Mos-
cow, reports the Russian Ministry of Finance, to 